Dapat diakses pada: http://jkb.ub.ac.id/index.php/jkb/article/view/1924

Jurnal Kedokteran Brawijaya Vol. 29, No. 04, Agustus 2017, pp. 335-340

Online Published First: 31 Agustus 2017

Article History: Received 17 Januari 2017, Accepted 28 April 2017

$\underline{\text { Artikel Penelitian }}$

\title{
Pola Pengobatan dan Fungsi Kognitif Pasien Epilepsi di RSJ Mutiara Sukma
}

\section{Treatment Pattern and Cognitive Function in Epilepsy Patients in Mutiara Sukma Mental Hospital}

\author{
Herpan Syafii $H^{1}$, Yanna Indrayana ${ }^{2}$ Emmy Amalia ${ }^{3}$ \\ ${ }^{1}$ Laboratorium Neurologi Fakultas Kedokteran Universitas Mataram \\ ${ }^{2}$ Laboratorium Ilmu Penyakit Jantung dan Pembuluh Darah Fakultas Kedokteran Universitas Mataram \\ ${ }^{3}$ Laboratorium Psikiatri Fakultas Kedokteran Universitas Mataram
}

\begin{abstract}
ABSTRAK
Epilepsi merupakan suatu gangguan pada sistem saraf pusat yang memiliki dampak neurobiologik, kognitif, psikologik, dan sosial. Penggunaan obat antiepilepsi diperlukan untuk mencegah komplikasi yang ditimbulkan oleh epilepsi. Salah satu komplikasi penting dari epilepsi adalah terjadinya gangguan fungsi kognitif. Penelitian ini bertujuan untuk mengetahui gambaran pola pengobatan dan fungsi kognitif pasien epilepsi di RSJ Mutiara Sukma Provinsi NTB. Sebanyak 97 subjek dilibatkan dalam penelitian potong lintang dengan pengambilan data meliputi usia, jenis kelamin, usia awitan bangkitan, tipe bangkitan, etiologi bangkitan, dan obat antiepilepsi yang digunakan. Fungsi kognitif dari 45 subjek penelitian diperiksa menggunakan instrumen MoCA-INA dan TMT-B. Perbandingan antara jenis OAE yang digunakan dan jumlah subjek dengan gangguan fungsi kognitif dianalisis dengan uji statistik Kai-kuadrat. Hasil penelitian menunjukkan $80,4 \%$ subjek mendapatkan monoterapi OAE. Monoterapi yang digunakan antara lain fenitoin (30,9\%), karbamazepin $(27,8 \%)$, dan asam valproat $(21,7 \%)$. Pada pemeriksaan MoCA-INA, $100 \%$ subjek mengalami gangguan fungsi kognitif. Pada pemeriksaan TMT-B, 91,11\% subjek memiliki hasil pemeriksaan tidak normal. Tidak terdapat perbedaan jumlah subjek dengan gangguan fungsi kognitif yang bermakna diantara berbagai kelompok yang mendapatkan OAE berbeda $(p=0,304)$. Dapat disimpulkan bahwa sebagian besar pasien epilepsi di RS ini mendapatkan monoterapi OAE fenitoin, mengalami gangguan fungsi kognitif terutama pada domain atensi dan fungsi eksekutif dan tidak ditemukan perbedaan antar jenis pengobatan.
\end{abstract}

Kata Kunci: Epilepsi, gangguan fungsi kognitif, obat antiepilepsi

\begin{abstract}
Epilepsy is a central nervous system disorder causing neurobiological, cognitive, psychological, and social impacts. The use of antiepileptic drugs is needed to prevent the complication of epilepsy. One of the most significant complication of epilepsy is cognitive dysfunction. This study was aimed to know the profile of treatment pattern and cognitive function in epilepsy patients in Mutiara Sukma Mental Hospital, West Nusa Tenggara. About 97 subjects were involved in this cross-sectional study, and the data collected were age, gender, onset of seizure, type of seizure, etiology, and antiepileptic drugs received by the patients. The assessment of cognitive function was conducted to 45 subjects by using MoCA-INA and TMT-B instruments. The comparison of antiepilepstic drugs (AEDs) used in this study and number of subjects showing cognitive impairment were analyzed by using Chi-square test. The result showed that $80,4 \%$ subjects received antiepileptic drug monotherapy. Monotherapies used were phenytoin (30,9\%), carbamazepine (27,8\%), and valproic acid (21,7\%). In MoCAINA assessment, 100\% subjects showed cognitive decline, while on TMT-B examination, $91,11 \%$ of subjects had abnormal examination results. There was no significant difference in number of subjects with significant cognitive impairment among AED groups $(p=0,304)$. In conclusion, most of the epilepsy patients in Mutiara Sukma Mental Hospital received antiepileptic drug monotherapy which was phenytoin. Most of the subjects showed cognitive dysfunction, especially in attention and executive function, but there was no difference between the treatment groups.
\end{abstract}

Keywords: Antiepileptic drugs, cognitive dysfunction, epilepsy

Korespondensi: Herpan Syafii H. Laboratorium Neurologi Fakultas Kedokteran Universitas Mataram, Jl. Pendidikan no. 37 Mataram Nusa Tenggara Barat 83125 Tel. 08175770062 Email: herpanharahap@yahoo.co.id

DOI: http://dx.doi.org/10.21776/ub.jkb.2017.029.04.9 


\section{PENDAHULUAN}

Epilepsi adalah suatu gangguan pada sistem saraf pusat yang ditandai dengan timbulnya bangkitan epileptik dengan dampak neurobiologik, kognitif, psikologik, dan sosial (1). Data prevalensi epilepsi di berbagai di dunia bervariasi, namun secara keseluruhan prevalensi epilepsi di dunia sebesar 10 per 1000 penduduk (2). Angka tersebut menjadi lebih tinggi di negara-negara berkembang, termasuk Indonesia, yaitu sebesar 10,3-15,4 per 1000 penduduk, baik pada populasi dewasa maupun anak-anak (3-5). Epilepsi dengan tipe bangkitan parsial, epilepsi lobus temporal, atau disebut juga dengan epilepsi parsial kompleks atau epilepsi psikomotor, memiliki prevalensi tertinggi, yaitu sekitar $60 \%$ dari total epilepsi dengan awitan usia dewasa (6). Data jumlah pasien epilepsi di Poli Saraf Rumah Sakit Jiwa (RSJ) Mutiara Sukma Provinsi Nusa Tenggara Barat (NTB) menurut rekapitulasi pada periode Juli 2015-Juni 2016 adalah sebanyak 181 orang $(47,63 \%)$ dan merupakan penyakit dengan angka kunjungan pasien tertinggi di poli saraf rumah sakit tersebut (7).

Epilepsi dapat diklasifikasikan berdasarkan tipe bangkitan dan sindrom epilepsinya. Mengacu pada klasifikasi menurut Commision on Classification and Terminology of the International League Against Epilepsy (ILAE) tahun 1981, terdapat tiga tipe yaitu bangkitan parsial sederhana dan parsial kompleks, dan bangkitan umum. Klasifikasi epilepsi berdasarkan sindromnya mengacu pada klasifikasi yang ditetapkan oleh ILAE tahun 1989, terdiri dari 4 sindrom, meliputi epilepsi yang berkaitan dengan letak fokus epileptogeniknya, epilepsi umum, epilepsi dan sindrom yang tidak dapat ditentukan fokal atau umum, dan sindrom khusus (8). Etiologi utama dari epilepsi antara lain cedera kepala, stroke, infeksi intrakranial, dan faktor genetik (2). Epilepsi yang disebabkan oleh faktor genetik atau diduga memiliki etiologi genetik dimasukkan dalam klasifikasi epilepsi idiopatik (9-10).

Obat antiepilepsi (OAE) diberikan begitu diagnosis epilepsi ditegakkan dan dimulai dengan monoterapi. Pemilihan OAE secara umum didasarkan pada klinis pasien dan ketersediaan dari berbagai jenis obat yang bisa digunakan. Obat antiepilepsi yang saat ini paling banyak digunakan antara lain karbamazepin, fenitoin, dan asam valproat, meskipun saat ini tersedia cukup banyak OAE yang relatif baru, seperti levetirasetam, lamotrigin, okskarbazepin, zonisamid, topiramat, dan sebagainya (11).

Salah satu komplikasi penting dan paling sering ditemukan akibat epilepsi adalah terjadinya gangguan fungsi kognitif, terutama pada kasus-kasus epilepsi yang berlangsung lama dan sulit untuk dikontrol (12). Gangguan kognitif tersebut bisa terjadi pada semua kelompok usia, termasuk anakanak $(13,14)$. Sekitar $10 \%$ penderita epilepsi kronik berusia kurang dari 40 tahun sudah menunjukkan terbentuknya plak senilis di jaringan otak (15). Beberapa penelitian menunjukkan bahwa pasien epilepsi mengalami gangguan fungsi kognitif, terutama pada fungsi domain kognitif spesifik, yaitu atensi, memori, dan fungsi eksekutif (16-18). Pemberian OAE pada pasien epilepsi ternyata dilaporkan juga memiliki efek negatif terhadap fungsi kognitif (12). Fenitoin, karbamazepin, dan asam valproat, OAE yang paling sering digunakan saat ini, dapat menyebabkan penurunan fungsi atensi dan memori, meskipun efek ketiga obat tersebut lebih ringan dibandingkan dengan benzodiazepin dan fenobarbital (19).
Penelitian ini bertujuan untuk mengetahui profil pola pengobatan dan fungsi kognitif pada pasien epilepsi di Rumah Sakit Jiwa (RSJ) Mutiara Sukma Provinsi Nusa Tenggara Barat (NTB). Penelitian ini merupakan penelitian awal untuk mengevaluasi fungsi kognitif dan efek pengobatan OAE terhadap fungsi kognitif pada pasien epilepsi di RSJ Provinsi NTB yang merupakan salah satu rumah sakit rujukan utama di tingkat provinsi dan dengan angka kunjungan rawat jalan pasien epilepsi yang tinggi yang berasal dari seluruh kabupaten di Provinsi NTB. Pentingnya dilakukan penelitian ini adalah untuk memberikan data dasar mengenai status fungsi kognitif pada pasien epilepsi di RSJ Mutiara Sukma, sehingga nantinya diharapkan bisa digunakan sebagai dasar penelitian lebih lanjut mengenai pengaruh penyakit epilepsi dan pemberian OAE terhadap fungsi kognitif pasien epilepsi, serta untuk penentuan kebijakan mengenai penggunaan OAE yang memiliki efek minimal terhadap fungsi kognitif berdasarkan penelitian lanjutan tersebut.

\section{METODE}

Penelitian ini merupakan penelitian deskriptif dengan rancangan potong lintang yang melibatkan 97 subjek penelitian yaitu penderita epilepsi yang menjalani pengobatan rawat jalan di Poli Saraf RSJ Mutiara Sukma Provinsi NTB dalam periode waktu 4 bulan, yaitu pada Bulan Agustus-November 2016. Pemeriksaan fungsi kognitif dikerjakan pada 45 subjek yang memenuhi kriteria inklusi dan eksklusi. Kriteria inklusi penelitian ini meliputi penderita epilepsi di rawat jalan Poli Saraf RSJ Mutiara Sukma, baik laki-laki maupun perempuan, yang berada dalam keadaan sadar penuh dan bersedia untuk berpartisipasi sebagai subjek penelitian. Kriteria eksklusi penelitian ini meliputi penderita epilepsi yang tidak dapat membaca dan menulis. Penelitian ini telah mendapatkan persetujuan dari Komisi Etik Penelitian Kesehatan Universitas Mataram dengan nomor surat persetujuan etik 106/UN18.8/ETIK/2016.

Dalam penelitian ini dilakukan pengambilan data yang meliputi karakteristik subjek penelitian dan hasil pemeriksaan fungsi kognitif. Data karakteristik subjek penelitian didapatkan melalui wawancara terstruktur terhadap subjek dan pendamping subjek yang memahami kondisi medis subjek tersebut. Data tersebut meliputi usia, jenis kelamin, usia awitan bangkitan, tipe bangkitan, etiologi bangkitan, dan obat antiepilepsi yang digunakan. Usia awitan bangkitan dikelompokkan menjadi $\geq 20$ tahun dan $<20$ tahun untuk mengetahui apakah epilepsi tersebut memiliki kecenderungan etiologi idiopatik. Suatu hasil penelitian menyebutkan bahwa epilepsi idiopatik cenderung ditemukan pada usia 20 tahun (20). Tipe bangkitan ditentukan berdasarkan klasifikasi yang ditetapkan oleh Commission on Classification and Terminology of ILAE tahun 1981 (8). Etiologi bangkitan dikelompokkan menjadi idiopatik, cedera kepala, stroke, infeksi intrakranial, dan penyebab lainnya. Pengelompokan etiologi epilepsi ini didasarkan pada referensi yang menyebutkan bahwa etiologi terbanyak dari epilepsi antara lain cedera kepala, stroke, infeksi intrakranial, dan idiopatik (2). Berdasarkan penggunaan $\mathrm{OAE}$, subjek dikelompokkan menjadi kelompok yang mendapatkan fenitoin, karbamazepin, asam valproat, dan terapi kombinasi. 
Data pemeriksaan fungsi kognitif yang diambil dari 45 subjek penelitian yang memenuhi kriteria inklusi dan eksklusi meliputi rerata usia subjek yang diperiksa, hasil pemeriksaan Montreal Cognitive Assessment yang saat ini tersedia dalam versi Indonesia (MoCA-INA) untuk penapisan fungsi kognitif secara global (21), dan hasil pemeriksaan Trail Making Test part B (TMT-B) untuk pemeriksaan domain atensi dan fungsi eksekutif (22). Data yang diambil dari pemeriksaan MoCA-INA adalah rerata skor MoCA-INA dan proporsi subjek dengan skor MoCA-INA $\geq 26$ dan $<26$. Subjek memiliki fungsi kognitif normal jika memiliki skor $\geq 26$ pada pemeriksaan MoCA (23). Dalam penelitian ini digunakan instrumen MoCA yang sudah diterjemahkan kedalam Bahasa Indonesia dan dikenal dengan MoCA versi Indonesia (MoCA-INA) dengan nilai titik potong normal yang sama (24). Berdasarkan hasil pemeriksaan TMT-B, subjek dikelompokkan menjadi kelompok dengan hasil pemeriksaan normal dan tidak normal. Subjek memiliki hasil pemeriksaan TMT-B normal jika mampu menyelesaikan tes tersebut dalam waktu $<180$ detik tanpa kesalahan berarti (25). Kajian awal mengenai perbandingan antara jenis OAE yang digunakan dan jumlah subjek dengan gangguan fungsi kognitif dilakukan dengan uji statistik Kai-kuadrat, dengan hasil uji bermakna jika nilai $p<0,05$.

\section{HASIL}

\section{Karakteristik Subjek Penelitian dan Pola Pengobatan Antiepilepsi}

Penelitian ini melibatkan 97 subjek dengan rerata usia $29,84 \pm 15,66$ tahun dengan proporsi jenis kelamin yang relatif sebanding antara laki-laki dan perempuan. Sebagian besar subjek penelitian memiliki awitan bangkitan pada usia dibawah 20 tahun, tipe bangkitan umum, dan mendapatkan monoterapi. Obat antiepilepsi yang paling sering digunakan untuk monoterapi pada subjek adalah fenitoin dan secara berturut-turut diikuti oleh karbamazepin, dan asam valproat. Kombinasi obat yang paling banyak digunakan adalah fenitoin dan asam valproat (Tabel 1).

Tabel 1. Karakteristik subjek penelitian dan pola pengobatan antiepilepsi

\begin{tabular}{|c|c|c|}
\hline Kategori & Subkategori & $\begin{array}{c}\text { Hasil } \\
(n=97)\end{array}$ \\
\hline $\begin{array}{l}\text { Usia dalam tahun } \\
\text { (rerata } \pm S D \text { ) }\end{array}$ & & $29,84 \pm 15,66$ \\
\hline \multirow[t]{2}{*}{ Jenis kelamin } & Laki-laki & $56(57,7 \%)$ \\
\hline & Perempuan & $41(42,3 \%)$ \\
\hline \multirow{2}{*}{$\begin{array}{l}\text { Usia awitan } \\
\text { bangkitan }\end{array}$} & $\geq 20$ tahun & $69(71,1 \%)$ \\
\hline & $<20$ tahun & $28(28,9 \%)$ \\
\hline \multirow[t]{3}{*}{ Tipe bangkitan } & Bangkitan parsial sederhana & $19(19,6 \%)$ \\
\hline & Bangkitan parsial kompleks & $20(20,6 \%)$ \\
\hline & Bangkitan umum & $58(59,8 \%)$ \\
\hline \multirow[t]{5}{*}{ Etiologi bangkitan } & Idiopatik & $64(66,0 \%)$ \\
\hline & Stroke & $22(22,7 \%)$ \\
\hline & Cedera kepala & $5(5,2 \%)$ \\
\hline & Infeksi intrakranial & $2(2,1 \%)$ \\
\hline & Lainnya & $4(4,1 \%)$ \\
\hline \multirow{4}{*}{$\begin{array}{l}\text { OAE yang } \\
\text { digunakan }\end{array}$} & Monoterapi & $78(80,4 \%)$ \\
\hline & Fenitoin & $30(30,9 \%)$ \\
\hline & Karbamazepin & $27(27,8 \%)$ \\
\hline & Asam valproat & $21(21,7 \%)$ \\
\hline
\end{tabular}

Tabel 1. Karakteristik subjek penelitian dan pola pengobatan antiepilepsi

\begin{tabular}{lcr}
\hline \multicolumn{1}{c}{ Kategori } & \multicolumn{1}{c}{ Subkategori } & \multicolumn{1}{c}{$\begin{array}{c}\text { Hasil } \\
(\mathbf{n = 9 7 )}\end{array}$} \\
\hline OAE yang & Kombinasi & $19(\mathbf{1 9 , 6 \% )}$ \\
digunakan & Fenitoin dan asam valproat & $7(\mathbf{7 , 2} \%)$ \\
& Karbamazepin dan asam valproat & $4(4,1 \%)$ \\
& Fenitoin dan karbamazepin & $3(3,1 \%)$ \\
& Karbamazepin dan luminal & $3(3,1 \%)$ \\
& Asam valproat dan luminal & $2(2,1 \%)$ \\
\hline
\end{tabular}

Keterangan: $\mathrm{OAE}=$ obat antiepilepsi

\section{Gambaran Fungsi Kognitif}

Pemeriksaan fungsi kognitif dilakukan terhadap 45 dari 97 subjek penelitian. Sebanyak 52 subjek tidak dapat dilakukan pemeriksaan fungsi kognitif, dengan rincian 3 subjek mengalami retardasi mental, 20 subjek buta huruf, dan 29 subjek menolak untuk dilakukan evaluasi fungsi kognitif. Rerata usia dari 45 subjek penelitian yang dilakukan pemeriksaan fungsi kognitif adalah 34,22 $\pm 13,10$ tahun. Pada uji penapisan fungsi kognitif secara global dengan instrumen MoCA-INA, seluruh subjek mengalami gangguan fungsi kognitif. Pada pemeriksaan fungsi kognitif pada domain fungsi eksekutif dengan instrumen TMT-B, sebagian besar subjek menunjukkan adanya gangguan fungsi eksekutif (Tabel 2). Tidak terdapat perbedaan yang bermakna jumlah subjek dengan gangguan fungsi kognitif pada berbagai kelompok yang mendapatkan jenis $\mathrm{OAE}$ yang berbeda $(p=0,304)$.

Tabel 2. Karakteristik usia dan hasil pemeriksaan fungsi kognitif pada subjek penelitian

\begin{tabular}{llr}
\hline \multicolumn{1}{c}{ Kategori } & Subkategori & \multicolumn{1}{c}{$\begin{array}{c}\text { Hasil } \\
(\mathbf{n}=\mathbf{4 5})\end{array}$} \\
\hline $\begin{array}{l}\text { Usia dalam tahun (rerata } \pm \text { SD) } \\
\text { Skor pemeriksaan MoCA-INA } \\
\text { (rerata } \pm \text { SD) }\end{array}$ & & $34,22 \pm 13,10$ \\
& & $15,40 \pm 6,49$ \\
& Skor $\geq 26$ & $0(0 \%)$ \\
TMT-B & Skor $<26$ & $45(100 \%)$ \\
& Normal & $4(8,89 \%)$ \\
\hline Keterangan: MoCA-INA=Montreal Cognitive Assessment versi Indonesia,
\end{tabular}

TMT-B=Trail Making Test part $B$

\section{DISKUSI}

Epilepsi merupakan kondisi medis yang menimbulkan dampak neurobiologik, kognitif, psikologik, dan sosial yang bermaka terhadap pasiennya. Hal ini disebabkan karena bangkitan yang terjadi dapat terus berulang sehingga menyebabkan kematian sel-sel neuron secara luas. Oleh karena itu, pemberian obat antiepilepsi (OAE) harus segera diinisiasi begitu diagnosis epilepsi telah ditegakkan. Inisiasi pemberian OAE idealnya menggunakan 1 jenis obat dengan dosis terendah yang efektif untuk mengontrol bangkitan, atau kita sebut juga dengan pemberian monoterapi. Pemberian monoterapi secara umum mampu mencegah timbulnya bangkitan pada $70 \%$ pasien (26). Saat ini sudah cukup banyak tersedia berbagai OAE yang bisa digunakan sebagai pilihan pengobatan. Pemilihan $\mathrm{OAE}$ idealnya memperhatikan profil efek samping obat, tipe 
bangkitan, dan pengalaman dokter dalam menggunakan obat, namun juga memperhatikan ketersediaan obat tersebut di lingkungan tempat tinggal pasien. Dalam penelitian ini, sebagian besar subjek mendapatkan monoterapi. Obat antiepilepsi yang paling banyak digunakan sebagai monoterapi adalah fenitoin, diikuti dengan karbamazepin dan asam valproat, sama dengan hasil penelitian mengenai penggunaan OAE konvensional di Turki dan India $(27,28)$.

Pemberian kombinasi dari 2 atau lebih OAE juga dipertimbangkan bila pemberian monoterapi OAE masih belum memberikan kontrol bangkitan yang baik. Sekitar 30-40\% pasien epilepsi tidak terkontrol dengan baik dengan pemberian monoterapi, sehingga harus dipertimbangkan untuk diberikan terapi kombinasi OAE (29), meskipun terapi kombinasi OAE umumnya lebih efektif dalam mengontrol bangkitan dibandingkan dengan penggunaan monoterapi, risiko terjadinya efek samping serius pada penggunaan terapi kombinasi tentunya menjadi lebih tinggi. Oleh karena itu, pemilihan OAE untuk terapi kombinasi harus hati-hati, dengan mempertimbangkan aspek interaksi antarobat, mekanisme kerja obat, dan efek samping obat. Saat ini masih belum ada bukti klinis yang menunjukkan bahwa kombinasi dari 2 obat tertentu lebih efektif dibandingkan dengan kombinasi 2 obat lainnya. Dalam penelitian ini proporsi subjek yang mendapatkan terapi kombinasi OAE sebesar 19,6\%. Kombinasi OAE yang paling sering digunakan adalah kombinasi antara fenitoin dan asam valproat, sedangkan kombinasi lain yang diberikan meliputi kombinasi antara karbamazepin dan asam valproat, fenitoin dan karbamazepin, karbamazepin dan luminal, dan asam valproat dan luminal memiliki proporsi yang lebih kecil.

Rerata usia subjek penelitian ini adalah 29,84 $\pm 15,66$ tahun dan proporsi usia awitan timbulnya bangkitan mayoritas adalah berusia kurang dari 20 tahun. Proporsi etiologi epilepsi yang tertinggi adalah idiopatik dan proporsi tipe bangkitan yang tertinggi adalah bangkitan umum sebanding dengan proporsi subjek yang berusia kurang dari 20 tahun. Epilepsi idiopatik cenderung ditemukan pada usia yang lebih muda, yaitu pada sekitar usia 20 tahun (20) dan dengan tipe bangkitan tonik klonik umum (2). Data tersebut didukung oleh hasil penelitian ini, Glauser et al. dalam telaahnya menunjukkan bahwa OAE yang tersedia untuk monoterapi, fenitoin, karbamazepin, dan asam valproat secara umum masih terbukti efektif untuk kontrol bangkitan pada pasien epilepsi, baik pada kelompok usia dewasa maupun anakanak dan pada tipe bangkitan parsial maupun umum (11). Ketiga obat tersebut banyak digunakan di negara-negara berkembang, termasuk Indonesia, karena ketersediaannya terjamin dan memiliki harga yang terjangkau (28). Oleh karena itu, ketiga obat tersebut rutin diberikan pada pasien epilepsi di RSJ Mutiara Sukma Provinsi NTB agar kepatuhan pasien terhadap pengobatan dapat dijaga.

Gangguan kognitif pada pasien epilepsi dapat merupakan komplikasi dari epilepsi atau merupakan dampak dari pengobatan epilepsi itu sendiri (12). Gangguan fungsi kognitif bisa terjadi setelah bangkitan pertama yang dialami oleh pasien epilepsi, baik pada anak-anak maupun pada orang dewasa (30). Sebagian besar pasien yang baru terdiagnosis epilepsi dan belum mendapatkan pengobatan mengalami gangguan fungsi kognitif, yaitu pada domain atensi, fungsi eksekutif, dan memori (17). Obat antiepilepsi, seperti yang telah disebutkan sebelumnya, ternyata juga dapat menimbulkan dampak negatif terhadap fungsi kognitif. Fenitoin, karbamazepin, dan asam valproat dilaporkan dapat menyebabkan gangguan fungsi atensi dan memori, dengan efek yang lebih ringan dibandingkan dengan yang ditimbulkan oleh benzodiazepin dan fenobarbital (19).

Untuk mengetahui adanya penurunan fungsi kognitif pada pasien epilepsi tersebut, maka perlu dilakukan pemeriksaan fungsi kognitif. Pemeriksaan MoCA-INA umumnya digunakan untuk penapisan adanya gangguan fungsi kognitif secara global, meliputi pemeriksaan visuospasial dan fungsi eksekutif, penamaan, atensi, bahasa, berpikir abstrak, memori tertunda, dan orientasi. Instrumen ini memiliki sensitivitas lebih baik dibandingkan dengan Mini-Mental State Examination (MMSE) yang terlebih dahulu banyak digunakan untuk penapisan fungsi kognitif secara global (31).

Dalam penelitian ini, seluruh subjek memiliki skor MoCAINA dibawah nilai normal. Hasil ini konsisten dengan hasil penelitian yang dilakukan oleh Phabphal dan Kanjasanitien terhadap 85 pasien epilepsi kriptogenik (21). Mengingat MoCA-INA merupakan instrumen yang digunakan untuk penapisan gangguan fungsi kognitif, maka hasil pemeriksaan dengan instrumen ini perlu dikonfirmasi dengan tes neuropsikologi yang spesifik untuk domain tertentu. Seperti yang telah disampaikan sebelumnya, pasien epilepsi cenderung mengalami gangguan fungsi kognitif pada domain atensi dan fungsi eksekutif. Untuk mengkonfirmasi adanya gangguan pada kedua domain fungsi kognitif tersebut, digunakan instrumen Trail Making Test part B (TMT-B) (32).

Hasil penelitian ini menunjukkan bahwa sebagian besar subjek (91,11\%) memiliki hasil pemeriksaan TMT-B tidak normal, yang menunjukkan bahwa sebagian besar subjek tersebut mengalami gangguan atensi dan fungsi eksekutif. Hasil tersebut juga konsisten dengan hasil penelitian yang dilakukan oleh Liik et al. yang juga melaukan evaluasi fungsi eksekutif dengan menggunakan instrumen yang sama terhadap 62 pasien epilepsi, baik fokal maupun general (33). Gangguan fungsi eksekutif tersebut dapat terjadi akibat gangguan pada jaras yang menghubungkan talamus dan lobus frontal akibat bangkitan yang tidak terkontrol dengan baik pada pasien epilepsi (30). Adanya proporsi kecil subjek yang memiliki atensi dan fungsi eksekutif normal, namun dengan fungsi kognitif global yang menurun, menunjukkan adanya penurunan fungsi pada domain kognitif lainnya, terutama pada domain memori.

Penurunan fungsi kognitif pada pasien epilepsi tersebut dapat terkait dengan penyakit epilepsi itu sendiri, OAE yang digunakan, atau kombinasi dari keduanya (12). Hasil kajian awal menunjukkan tidak terdapat perbedaan jumlah subjek dengan gangguan fungsi kognitif yang bermakna pada berbagai kelompok yang medapatkan jenis OAE yang yang berbeda. Hal ini berarti bahwa semua OAE yang digunakan oleh subjek dalam penelitian ini memberikan efek penurunan fungsi kognitif yang sebanding. Perlu dilakukan penelitian lebih lanjut untuk mengkonfirmasi apakah gangguan fungsi kognitif yang dialami subjek tersebut merupakan akibat yang ditimbulkan oleh epilepsi atau akibat dari penggunaan OAE.

Penyebab terjadinya gangguan kognisi pada subjek 
penelitian ini bersifat multifaktorial. Gangguan kognisi pada subjek penelitian ini kemungkinan dapat terjadi karena adanya interaksi antara lokasi fokus epileptogenik dan bangkitan yang tidak terkontrol. Secara teori, bangkitan yang tidak terkontrol dengan baik menyebabkan kerusakan neuron pada lokasi otak tertentu akan menentukan pola gangguan kognisi pada pasien tersebut. Sebagai contoh, fokus epileptogenik pada hipokampus dan lobus temporal mesial akan memberikan manifestasi gangguan memori yang lebih menonjol dibandingkan dengan domain kognisi lainnya. Pada contoh lain, gangguan talamokortikal pada pasien epilepsi dengan tipe bangkitan umum, akan menyebabkan pasien tersebut mengalami gangguan pada domain atensi, bahasa, dan fungsi eksekutif (31). Gangguan kognisi pada pasien ini kemungkinan juga bisa disebabkan karena penggunaan OAE. Obat antiepilepsi yang dikonsumsi oleh subjek penelitian ini adalah OAE konvensional, antara lain luminal, fenitoin, karbamazepin, dan asam valproat, yang

\section{DAFTAR PUSTAKA}

1. Fisher RS, Acevedo C, Arzimanoglou A, et al. ILAE Official Report: A Practical Clinical Definition of Epilepsy. Epilepsia. 2014; 55(4): 475-482.

2. Shakirullah, Ali N, Khan A, and Nabi M. The Prevalence, Incidence, and Etiology of Epilepsy. International Journal of Clinical and Experimental Neurology. 2014; 2(2): 29-39.

3. Ngugi AK, Bottomley C, Kleinschmidt I, Sander JW, and Newton CR. Estimation of the Burden of Active and Life-time Epilepsy: A Meta-Analytic Approach. Epilepsia. 2010; 51(5): 883-890.

4. Russ SA, Larson K, and Halfon N. A National Profile of Childhood Epilepsy and Seizure Disorder. Pediatrics. 2012; 129(2): 256-264.

5. Bell GS, Neligan A, and Sander JW. An Unknown Quantity - The Worldwide Prevalence of Epilepsy. Epilepsia. 2014; 55(7): 958-962.

6. Tellez-Zenteno JF and Hernandez-Ronquillo L. A Review of the Epidemiology of Temporal Lobe Epilepsy. Epilepsy Research and Treatment. 2012; 2012: 1-5.

7. Komite Peningkatan Mutu dan Keselamatan Pasien RSJ Mutiara Sukma. Laporan Program Kerja Tahun 2015-2016. Mataram: RSJ Mutiara Sukma; 2016.

8. Berg AT and Scheffer IE. New Concepts in Classification of the Epilepsy: Entering the 21st Century. Epilepsia. 2011; 52(6): 1058-1062.

9. Wong M. Juvenile Myoclonic Epilepsy: Is It An Idiopathic Epilepsy Caused by a Malformation of Cortical Development? Epilepsy Currents. 2010; 10(3): 69-71.

10. Shorvon SD. The Etiologic Classification of Epilepsy. Epilepsia. 2011; 52(6): 1052-1057.

11. Glauser T, Ben-Menachem E, Bourgeois B, et al. Updated ILAE Evidence Review of Antiepileptic Drug Efficacy and Effectiveness as Initial Monotherapy for Epileptic Seizures and Syndromes. Epilepsia. 2013; 54(3): 551-563.

12. Helmstaedter C. The Impact of Epilepsy on Cognitive diketahui dapat menyebabkan penurunan fungsi kognitif, terutama pada domain memori dan atensi. Efek OAE tersebut secara teori dikaitkan dengan terjadinya peningkatan stres oksidatif di jaringan otak, sehingga menyebabkan terjadinya kerusakan neuronal dan gangguan kognisi. Gangguan kognisi terkait OAE tersebut menurut penelitian sebelumnya pada umumnya bersifat reversibel, artinya dengan penurunan dosis atau penghentian $O A E$, fungsi kognitif bisa mengalami perbaikan (19). Perlu dilakukan penelitian lebih lanjut untuk mengkonfirmasi peran lokasi fokus epileptogenik dan penggunaan OAE terhadap terjadinya gangguan kognisi pada pasien epilepsi.

Penelitian ini menunjukkan bahwa monoterapi dengan OAE dengan fenittoin merupakan pola terbanyak. Gangguan fungsi kognitif banyak ditemukan, terutama pada domain atensi dan fungsi eksekutif, namun tidak ada perbedaan jenis OAE.

Function (Abstract). Journal of Neurology Neurosurgery Psychiatry. 2013; 84: e1.

13. Guzeva VI, Belash VO, Guseva VV, Guzeva OV, and Anastazi IEO. Characteristics of Cognitive Functions in Children with Epilepsy. Neuroscience and Behavioral Physiology. 2009; 39(9): 885-889.

14. Nehra A, Tripathi M, Bhatia R, et al. Is Epilepsy a Cause of Cognitive Decline in Developing Brain. Activitas Nervosa Superior. 2013; 55(3): 112-117.

15. Hermann B, Seidenberg M, Sager M, et al. Growing Old with Epilepsy: The Neglected Issue of Cognitive and Brain Health in Aging and Elder Persons with Chronic Epilepsy. Epilepsia. 2008; 49(5): 731-740.

16. Guilhoto LMFF, Fernandes RDC, Pacheco SP, Ballester $D$, and Gilio AE. Benign Focal Seizures of Adolescence and Neuropsychological Findings in Patients from Community. Journal of Epilepsy Clinical Neurophysiology. 2009; 15(4): 184-191.

17. Witt JA and Helmstaedter C. Should Cognition be Screened in New-Onset Epilepsies? A Study in 247 Untreated Patients. Journal of Neurology. 2012; 259(8): 1727-1731.

18. Azizova RB. New Aspects of the Pathogenesis of Epilepsy. European Medical, Health and Pharmaceutical Journal. 2014; 7(2): 3-5.

19. Witt JA and Helmstaedter C. Monitoring the Cognitive Effects of Antiepileptic PharmacotherapyApproaching the Individual Patient. Epilepsy Behavior. 2013; 26(3): 450-456.

20. Asadi-Pooya AA, Emami M, and Sperling MR. Age of Onset in Idiopathic (Genetic) Generalized Epilepsies: Clinical and EEG Findings in Various Age Groups. Seizure. 2012; 21(6): 417-421.

21. Phabphal $\mathrm{K}$ and Kanjanasatien J. Montreal Cognitive Assessment in Cryptogenic Epilepsy Patients with Normal Mini-mental State Examination Scores. Epileptic Disorders. 2011; 13(4): 375-381.

22. Salthouse TA. What Cognitive Abilities are Involved in Trail-making Performance? Intelligence. 2011; 39(4): 222-232. 
23. Zuo L, Dong Y, Zhu R, et al. Screening for Cognitive Impairment with the Montreal Cognitive Assessment in Chinese Patients with Acute Mild Stroke and Transient Ischemic Attack: A Validation Study. British Medical Journal Open. 2016; 6(7): e011310.

24. Prasetyo BT, Lumempouw SF, Ramli Y, dan Herqutanto. Nilai Normal Montreal Cognitive Assessement Versi Indonesia (MoCA-INA). Neurona. 2011; 29(1): 5-13.

25. Kelompok Studi Fungsi Luhur. Panduan Pemeriksaan Neurologi dan Neurobehavior. Jakarta: PERDOSSI; 2010; hal. 1-12.

26. Sarhan E, Walker MC, and Selai C. Evidence for Efficacy of Combination of Antiepileptic Drugs in Treatment of Epilepsy. Journal of Neurology Research. 2015; 5(6): 267-276.

27. Simargul B, Atli $O$, and Ilgin S. The Effect of Combination Therapy on the Plasma Concentrations of Traditional Antiepileptics: A Retrospective Study. Human and Experimental Toxicology. 2012; 31(10): 971-980.

28. Naithani M. The Conventional Antiepileptic Drug Use When Compared to a Combination Therapy Regime in a Teaching Hospital in India. International Journal of Pharma and Bio Sciences. 2012; 3(1): 191-197.

29. Lee JW and Dworetzky B. Rational Polytherapy with Antiepileptic Drugs. Pharmaceuticals. 2010; 3(8): 2362-2379.

30. Lin JJ, Mula M, and Hermann BP. Uncovering the Neurobehavioural Comorbidities of Epilepsy Over the Lifespan. The Lancet. 2012; 380: 1180-1192.

31. Dong Y, Sharma VK, Chan BP, et al. The Montreal Cognitive Assessment (MoCA) is Superior to the MiniMental State Examination (MMSE) for the Detection of Vascular Cognitive Impairment after Acute Stroke. Journal of the Neurological Sciences 2010; 299(1-2): 15-18.

32. Sanchez-Cubillo I, Perianez JA, Adrover-Roig D, et al. Construct Validity of The Trail Making Test: Role of Task-Switching, Working Memory, Inhibition/Interference Control, and Visuomotor Abilities. Journal of the International Neuropsychological Society. 2009; 15(3): 438-450.

33. Liik M, Vahter L, Gross-Paju K, and Haldre S. Cognitive Profile and Depressive Symptoms in Patients with Epilepsy. Medicina (Kaunas). 2013; 49(6): 254-261. 